\title{
Caracterização de genótipos de tomateiro resistentes a begomovírus por marcador molecular co-dominante ligado ao gene Ty-1
}

\author{
Daniela Aparecida de Castro Nizio(1), Wilson Roberto Maluf(2), Antônia dos Reis Figueira(3), \\ Douglas Willian Nogueira(1), Vanisse de Fátima Silva ${ }^{(2)}$ e Álvaro Carlos Gonçalves Neto(2)
}

\begin{abstract}
(1)Universidade Federal de Lavras (Ufla), Departamento de Biologia, Caixa Postal 3037, CEP 37200-000 Lavras, MG. E-mail: danielanizio@yahoo.com.br, douglagen@yahoo.com.br (2)Ufla, Departamento de Agricultura. E-mail: wrmaluf@ufla.br, vanissesilva@yahoo.com, alvarocgneto@gmail.com (3)Ufla, Departamento de Fitopatologia. E-mail: antonia@ufla.br
\end{abstract}

\begin{abstract}
Resumo - $\mathrm{O}$ objetivo deste trabalho foi avaliar genótipos de tomateiro, quanto à resistência a begomovírus, e caracterizar, por meio do marcador molecular SSR-47, híbridos de tomate de mesa portadores do alelo de resistência ao begomovírus $T y$ - 1 , com potencial comercial. Os 24 híbridos experimentais, heterozigotos no loco $T y$-1, depois de infectados via enxertia, apresentaram sintomas intermediários, em comparação aos identificados pelas linhagens homozigotas $T y-1 / T y-1$ e pelos genótipos suscetíveis $T y-1^{+} / T y-1^{+}$, o que indica a dominância incompleta do alelo $T y-1$. Esses híbridos foram considerados como parcialmente tolerantes a begomovírus. Os híbridos experimentais TEX-246, TEX-261, TEX-253, TEX-256, TEX-262, TEX-252, TEX-251 e TEX-268 aliaram médias elevadas de produção total e de massa média dos frutos; e os híbridos TEX-246, TEX-253, TEX-256, TEX-262 e TEX-252 apresentaram valores elevados também para meia-vida da firmeza e foram, portanto, considerados competitivos em comparação aos padrões comerciais usados como testemunhas. O marcador molecular SSR-47 foi eficiente em caracterizar genótipos portadores do alelo Ty-1. A infecção do begomovírus, induzida via enxertia, manifestou sintomas, nos genótipos testados, condizentes com os resultados obtidos com o marcador molecular SSR-47.
\end{abstract}

Termos para indexação: Lycopersicon esculentum, geminivírus, microssatélite, resistência.

\section{Fingerprinting of tomato genotypes resistant to begomovirus by a codominant molecular marker linked to Ty-1 gene}

\begin{abstract}
The objectives of this study were to evaluate tomato genotypes for begomovirus resistance and to assess SSR-47 fingerprinting patterns associated with alleles Ty-1, in hybrids of fresh-market tomato with commercial potential. Twenty-four experimental genotypes, heterozygous at $T y-1$ locus, were infected with begomovirus via grafting, and showed intermediate symptoms compared to the ones identified by homozygous $T y-1 / T y-1$ lines and by susceptible genotypes $T y-1^{+} / T y-1^{+}$, which indicates the incomplete dominance of the $T y-1$ allele. These hybrids were considered to possess partial resistance to begomovirus. The experimental hybrids TEX-246, TEX-261, TEX-253, TEX-256, TEX-262, TEX-252, TEX-251 and TEX-268 combined high total yields with high mean fruit mass. The hybrids TEX-246, TEX-253, TEX-256, TEX-262 and TEX-252 showed also longer half-life for fruit firmness and were thus considered competitive with current commercial hybrids used as checks. The molecular marker SSR-47 was effective for fingerprinting of tomato genotypes bearing the resistance allele $T y-1$. The graft-induced infection of begomovirus showed symptoms in the genotypes tested that are in agreement with the results of fingerprinting with the marker SSR- 47.
\end{abstract}

Index terms: Lycopersicon esculentum, geminivirus, microsatellite, resistance.

\section{Introdução}

As geminiviroses constituem doenças que causam perdas significativas na cultura do tomateiro, nas principais regiões do mundo onde essa solanácea é cultivada (Faria et al., 2000; Moriones \& Navas Castillo, 2000).

Entre os geminivírus (família Geminiviridae), o gênero que infecta o tomate (Lycopersicon esculentum) é classificado como Begomovirus, e é transmitido pela mosca-branca do gênero Bemisia. Os begomovírus podem apresentar genoma bipartido ou monopartido. No Brasil, diversos surtos de geminiviroses foram observados em tomateiro, principalmente após a introdução do biótipo B do vetor Bemisia tabaci, e, hoje, além de quatro espécies reconhecidas, outras dez espécies "provisórias" de begomovírus foram identificadas infectando essa cultura(Ribeiro etal., 2003). Os principais

Pesq. agropec. bras., Brasília, v.43, n.12, p.1699-1705, dez. 2008 
sintomas causados são enrolamento da folha, epinastia, mosaico-dourado, rugoses, cloroses nervais, cloroses internervais, mosqueado e atrofia que resultam em redução da floração, paralisação no crescimento e conseqüente perda na produção, principalmente se a infecção das plantas ocorrer nos estádios iniciais de desenvolvimento (Zhou et al., 2008).

O desenvolvimento de cultivares de tomateiro com resistência a begomovírus constitui o melhor método de controle da doença. Na Europa, acessos tolerantes a begomovírus, com genoma monopartido, foram também tolerantes a alguns isolados com genoma bipartido (Santana et al., 2001; Matos et al., 2003), a partir da introgressão do alelo $T y$ - 1 da espécie selvagem L. chilense. Estudos recentes, realizados no Brasil, mostraram que o loco $7 y$ - 1 confere reação de tolerância a distintas espécies de Begomovirus bipartidos (Boiteux et al., 2007).

No processo de transferência de alelos de resistência, os marcadores moleculares do DNA podem ser uma ferramenta bastante útil. Esses marcadores, se ligados aos alelos de resistência, podem ser usados na seleção assistida por marcadores (SAM), nas etapas iniciais e intermediárias do melhoramento.

A identificação de marcadores moleculares ligados a alelos de resistência a doenças vem sendo um dos principais objetivos dos programas de melhoramento genético em andamento no mundo para a cultura do tomateiro. O marcador molecular microssatélite SSR-47 é mapeado num cluster gênico no cromossomo 6 do tomateiro a uma distância menor que $1 \mathrm{cM}$ do loco Mi (Sol Genomics Network, 2008), por sua vez intimamente ligado ao loco Ty-1 (Zamir et al., 1994).
O objetivo deste trabalho foi avaliar linhagens e híbridos de tomateiro, quanto à resistência a begomovírus, e caracterizar, por meio do marcador molecular SSR-47, híbridos de tomateiro de mesa com potencial comercial, resistentes a begomovírus e portadores do alelo de resistência $T y-1$.

\section{Material e Métodos}

Os experimentos foram realizados em campo, na estação experimental da empresa HortiAgro Sementes Ltda., e em casa de vegetação e Laboratório de Virologia Molecular do Departamento de Fitopatologia da Universidade Federal de Lavras, entre agosto de 2007 e março de 2008.

Foramavaliados 24 híbridosexperimentais $\mathrm{F}_{1}$, obtidos por cruzamentos entre linhagens avançadas de tomateiro (Tabela 1), nove linhagens avançadas - previamente selecionadas para resistência a begomovírus, pelo Programa de Melhoramento Genético de Hortaliças da Ufla/HortiAgro Sementes Ltda., que foram utilizadas como parentais femininos na obtenção dos híbridos experimentais - e quatro híbridos comerciais, sabidamente suscetíveis a begomovírus, utilizados como testemunhas. Os híbridos experimentais foram: TEX-245 $=\mathrm{F}_{1}$ (TOM-694 $\times$ TOM-700), TEX-246 = $\mathrm{F}_{1}$ (TOM-695 x TOM-700), TEX-247 $=\mathrm{F}_{1}$ (TOM-696 $\mathrm{x}$ TOM-700), TEX-248 = $\mathrm{F}_{1}(\mathrm{TOM}-697 \times \mathrm{TOM}-700)$, TEX-249 $=\mathrm{F}_{1}(\mathrm{TOM}-691 \times \mathrm{TOM}-700)$, TEX-250 $=\mathrm{F}_{1}$ (TOM-692 x TOM-700), TEX-251 = $\mathrm{F}_{1}$ (TOM-693 x TOM-700), TEX-252 = $\mathrm{F}_{1}$ (TOM-698 x TOM-700), TEX-253 $=F_{1}($ TOM-699 $\times$ TOM-700), TEX-254 = $\mathrm{F}_{1}$ (TOM-694 x TOM-684), TEX-255 = $\mathrm{F}_{1}$ (TOM-695 x TOM-684), TEX-256 = F 1 (TOM-696 x TOM-684),

Tabela 1. Descrição dos genitores utilizados na obtenção dos híbridos experimentais.

\begin{tabular}{|c|c|}
\hline Genitores & Descrição $^{(1)}$ \\
\hline & Femininos \\
\hline TOM-694, TOM-695, ТOM-696, ТOM-697 & $\begin{array}{l}\text { Linhagens com "background" comum, do tipo Santa Clara, de crescimento } \\
\text { indeterminado. Possuem os alelos de resistência: } S w-R T \text { e } T y-1\end{array}$ \\
\hline TOM-691, ТOМ-692, ТOM-693 & Linhagens com "background" comum, do tipo Rio Grande, de crescimento determinado. \\
\hline & Possuem os alelos de resistência: $S w-5$ e $T y-1$ \\
\hline TOM-698 е ТOM-699 & $\begin{array}{l}\text { Linhagens com "background" comum, do tipo Rio Grande, de crescimento determinado. } \\
\text { Possuem os alelos de resistência: } S w-R T \text { e } T y-1\end{array}$ \\
\hline & $\begin{array}{cc} & \text { Masculinos } \\
& \end{array}$ \\
\hline TOM-700 е TOM-684 & $\begin{array}{l}\text { Linhagens com "background" comum, tipo Santa Clara, de crescimento indeterminado. } \\
\text { Possuem os alelos de resistência: } M i \text { e } S w-5\end{array}$ \\
\hline TOM-598 e TOM-658 & $\begin{array}{l}\text { Linhagens com "background" comum, do tipo Rio Grande, de crescimento } \\
\text { indeterminado. Possuem o alelo de resistência: } M i\end{array}$ \\
\hline
\end{tabular}

(1) Mi, Meloidogyne spp.; Sw-5, tospovirus (fonte de resistência: cv. Stevens); Sw-RT, tospovirus (fonte de resistência: cv. Rey de Los Tempranos); Ty-1, Begomovirus. 
TEX-257 $=\mathrm{F}_{1}\left(\right.$ TOM-697 $\times$ TOM-684), TEX-258 $=\mathrm{F}_{1}$ (TOM-691 x TOM-684), TEX-259 = F 1 (TOM-692 $\mathrm{x}$ TOM-684), TEX-260 = F $($ TOM-693 x TOM-684), TEX-261 $=\mathrm{F}_{1}(\mathrm{TOM}-698 \times \mathrm{TOM}-684)$, TEX-262 = $\mathrm{F}_{1}(\mathrm{TOM}-699 \times \mathrm{TOM}-684)$, TEX-263 = $\mathrm{F}_{1}$ (TOM-694 x TOM-598), TEX-264 = F $($ TOM-691 x TOM-598), TEX-265 $=\mathrm{F}_{1}(\mathrm{TOM}-698 \times \mathrm{TOM}-598), \mathrm{TEX}-266=\mathrm{F}_{1}$ (TOM-694 x TOM-658), TEX-267 = F 1 (TOM-691 x TOM-658) e TEX-268 = $\mathrm{F}_{1}$ (TOM-698 x TOM-658). Os híbridos comerciais foram: Bônus $\mathrm{F}_{1}$, Bravo $\mathrm{F}_{1}$, Débora Max e Pérola $F_{1}$. As linhagens genitoras foram: TOM-691, TOM-692, TOM-693, TOM-694, TOM-695, TOM-696, TOM-697, TOM-698 е TOM-699.

A enxertia por garfagem foi realizada 15 dias após o transplantio, com o uso de estacas das plantas de tomateiro da cultivar Santa Clara - com sintomas nítidos e severos da infecção por begomovírus -, que foram exertadas nas plantas a serem avaliadas. $\mathrm{O}$ inóculo utilizado foi anteriormente identificado pelo laboratório de Virologia da Ufla como pertencente ao gênero Begomovirus, contudo a identificação da espécie ainda não havia sido realizada. As avaliações foram feitas em cada planta, aos 46 e 60 dias após a enxertia, levando-se em consideração os sintomas nas brotações novas, empregando-se uma escala de notas de 1 a 5, adaptada de Lourenção et al. (2004), em que: 1, ausência de sintomas; 2 , maioria das folhas com sintomas brandos - como leve mosaico e leve rugosidade; 3, algumas folhas com rugose nítida, e sintomas variando de clorose, em até $50 \%$ da área foliar, a leves deformações nas folhas; 4, maioria das folhas com rugosidade severa, clorose acima de $50 \%$ da área foliar e folhas deformadas; 5, folhas com rugosidade severa, enrolamento das folhas, encarquilhamento, clorose e deformações severas.

$\mathrm{O}$ experimento foi realizado em delineamento inteiramente ao acaso, com 37 tratamentos e quatro repetições, sendo cada planta uma repetição. As diferenças entre tratamentos foram verificadas pelo teste de Duncan. Foram estimados os seguintes contrastes: genótipos homozigotos resistentes $\mathrm{x}$ genótipos suscetíveis; genótipos heterozigotos $\mathrm{x}$ genótipos suscetíveis; e genótipos homozigotos resistentes x genótipos heterozigotos. Em seguida, foi estimado o grau médio de dominância de $T y-1$.

Para verificar a presença do marcador ligado ao alelo $T y$ - 1 , foram avaliados todos os tratamentos citados na etapa anterior, além dos genótipos testemunhas TEX-143 (Ty-1/Ty-1 $\left.{ }^{+}\right)$, LA-3473 (Ty-1/Ty-1) e LA-3475
$\left(T y-1^{+} / T y-1^{+}\right)$, que são: heterozigoto, homozigoto resistente e homozigoto suscetível, para o loco $T y$-1, respectivamente. O DNA dos genótipos foi extraído em microtubos de $1,5 \mathrm{~mL}$, a partir de $120 \mathrm{mg}$ de tecido foliar, conforme sugerido por Ferreira \& Gratapaglia (1998), com adaptações. O DNA foi extraído de um bulk, composto por tecido foliar de oito plantas de cada tratamento.

Para a PCR, foi preparado um mix por amostra com 2,5 $\mu \mathrm{L}$ de tampão PCR $10 \mathrm{X} ; 0,75 \mu \mathrm{L} \mathrm{MgCl}_{2}$ $50 \mathrm{mM} ; 0,50 \mu \mathrm{L}$ de dNTP $10 \mu \mathrm{mM} ; 1,25 \mu \mathrm{L}$ de cada primer (forward $=$ TCCTCAAGAAATG e reverse $=$ CCTTGGAGATAA), a $10 \mathrm{mM}$ (Frary et al., 2005); $0,25 \mu \mathrm{L}$ Taq polimerase (5 unidades por $\mu \mathrm{L}$ ); 1,0 $\mu \mathrm{L}$ de DNA $20-50 \mathrm{ng} ; 17,5 \mu \mathrm{L}$ de $\mathrm{H}_{2} \mathrm{O}$ ultrapura, autoclavada.

A amplificação foi inicialmente conduzida por $5 \mathrm{~min}$, a $94^{\circ} \mathrm{C}$, seguidos por 35 ciclos de $30 \mathrm{~s}$, a $94^{\circ} \mathrm{C}$; $45 \mathrm{~s}$, a $45^{\circ} \mathrm{C}$; e $2 \mathrm{~min}$, a $72^{\circ} \mathrm{C}$. A reação final de elongação foi de $5 \mathrm{~min}$, a $72^{\circ} \mathrm{C}$. A separação dos fragmentos foi realizada em gel de poliacrilamida $15 \%$, em tampão TBE 1X. A coloração foi feita com brometo de etídeo e as bandas no gel foram visualizadas em luz ultravioleta, a $260 \mathrm{~nm}$, e fotografadas.

O marcador SSR-47 (Sol Genomics Network, 2008) resulta na amplificação de fragmentos de DNA com 191 pb e 180 pb (Frary et al., 2005). O padrão das bandas obtido foi comparado com as testemunhas.

Para a avaliação agronômica, o experimento constituiu-se de 24 híbridos experimentais e quatro híbridos comerciais. Vinte e três dias após a semeadura, as mudas foram transplantadas para o campo. O experimento foi conduzido no delineamento em blocos ao acaso, com 28 tratamentos e três repetições. Cada parcela constituiu-se de uma fileira com 12 plantas, com espaçamento de $1 \mathrm{~m}$ entre linhas e $0,50 \mathrm{~m}$ entre plantas, equivalente a 20.000 plantas $\mathrm{ha}^{-1}$. Os tratos culturais e fitossanitários seguiram recomendações específicas para a cultura do tomateiro. As plantas foram conduzidas em haste única, com tutoramento vertical. Foram realizadas 13 colheitas, no período de 19 de junho a 23 de agosto de 2007, e as seguintes características foram avaliadas: produção total de frutos, produção precoce de frutos (referente às quatro primeiras colheitas), massa média dos frutos, firmeza inicial do fruto no estádio "breaker" de maturação e meia-vida da firmeza. A firmeza dos frutos foi medida segundo a técnica de aplanação não-destrutiva, desenvolvida 
por Calbo \& Calbo (1989) e Calbo \& Nery (1995), e a meia-vida da firmeza calculada segundo Cá (2005) e Faria (2006). Os tratamentos foram comparados pelo teste de Tukey, a $5 \%$ de probabilidade.

\section{Resultados e Discussão}

Aos 46 e 60 dias após a enxertia (DAE), os híbridos comerciais obtiveram notas médias de severidade da doença acima de 4, as quais diferiram significativamente das médias dos demais tratamentos e permitiram classificar esses híbridos como altamente suscetíveis (Tabela 2). Nesse mesmo período, as notas médias apresentadas pelos híbridos experimentais situaram-se entre 2 e 3 , o que os caracterizou como tolerantes a begomovírus. Os híbridos experimentais responderam à infecção por begomovírus de forma semelhante aos genótipos heterozigotos para o loco $T y$ - 1 , em ensaios realizados no continente Europeu, Oriente Médio e no Brasil (Lapidot et al., 1997; Boiteux et al., 2007), nos quais foi observada a presença de plantas sintomáticas e com infecção sistêmica do vírus. No entanto, em todos esses ensaios, a expressão dos sintomas nos genótipos heterozigotos para o loco $T y-1$ foi mais suave do que aquela apresentada pelos genótipos suscetíveis.

As linhagens se destacaram por apresentar as notas mais baixas (algumas próximas de 1), nas duas avaliações, o que caracterizou genótipos resistentes a begomovírus. Boiteux et al. (2007) verificaram que genótipos heterozigotos $\left(T y-1 / T y-1^{+}\right)$e homozigotos suscetíveis $\left(T y-1^{+} / T y-1^{+}\right)$apresentaram 35 e 95\%, respectivamente, de plantas com sintomas de infecção por begomovírus, após serem submetidas a condições de inóculo natural sob elevada densidade populacional de mosca-branca virulífera. No entanto, esses autores não avaliaram genótipos homozigotos resistentes $(T y-1 / T y-1)$.

As estimativas dos contrastes e dos efeitos gênicos envolvidos foram significativas para as duas avaliações (Tabela 3). Os genótipos suscetíveis apresentaram, em média, 2,89 e 3,04 pontos a mais, na escala de sintomas, do que os genótipos homozigotos resistentes, aos 46 e 60 dias após a enxertia, respectivamente. Por outro lado, os genótipos suscetíveis exibiram, em média, 2,12 e 2,48 pontos a mais, na escala de sintomas, que os genótipos heterozigotos, aos 46 e 60 dias após a enxertia, respectivamente. Esse resultado demonstra que os genótipos heterozigotos para o loco $T y-1$ exibem sintomas sensivelmente mais brandos do que os suscetíveis, porém, mais acentuados do que os homozigotos resistentes. O loco $T y l$ confere reação de tolerância a distintas espécies de Begomovirus (Santana et al., 2001; Matos et al., 2003; Boiteux et al., 2007). Assim, mesmo algumas plantas homozigotas para o loco $T y$-1, exibem sintomas de infecção sistêmica pelo vírus.

As estimativas do grau de dominância (A/D) do loco Ty-1, aos 46 e aos 60 dias após a enxertia, situaram-

Tabela 2. Médias das notas para resistência a begomovírus, em genótipos de tomateiro, aos 46 e 60 dias após a enxertia $^{(1)}$.

\begin{tabular}{|c|c|c|}
\hline \multirow[t]{2}{*}{ Tratamentos } & \multicolumn{2}{|c|}{ Médias } \\
\hline & 46 dias & 60 dias \\
\hline TEX-245 & $2,50 \mathrm{ef}$ & $2,25 \mathrm{cdefg}$ \\
\hline TEX-246 & $2,50 \mathrm{cde}$ & $2,50 \mathrm{bcdef}$ \\
\hline TEX-247 & $2,50 \mathrm{ef}$ & $2,25 \mathrm{cdefg}$ \\
\hline TEX-248 & $2,00 \mathrm{cde}$ & $2,25 \mathrm{cdefg}$ \\
\hline TEX-249 & $2,33 \mathrm{def}$ & 2,33defg \\
\hline TEX-250 & $2,25 \mathrm{def}$ & $2,25 \mathrm{cdefg}$ \\
\hline TEX-251 & $2,25 \mathrm{def}$ & $2,75 \mathrm{fg}$ \\
\hline TEX-252 & $2,00 \mathrm{cde}$ & 2,00bcdef \\
\hline TEX-253 & $2,50 \mathrm{ef}$ & $2,25 \mathrm{cdefg}$ \\
\hline TEX-254 & $2,25 \mathrm{def}$ & 2,00bcdef \\
\hline TEX-255 & $2,25 \mathrm{def}$ & $2,25 \mathrm{cdefg}$ \\
\hline TEX-256 & $2,00 \mathrm{cde}$ & $2,00 \mathrm{bcdef}$ \\
\hline TEX-257 & $2,25 \mathrm{def}$ & $2,25 \mathrm{cdefg}$ \\
\hline TEX-258 & $2,25 \mathrm{def}$ & $2,25 \mathrm{cdefg}$ \\
\hline TEX-259 & $2,50 \mathrm{ef}$ & $2,50 \mathrm{efg}$ \\
\hline TEX-260 & $2,50 \mathrm{ef}$ & $2,50 \mathrm{efg}$ \\
\hline TEX-261 & 2,00 cde & 2,00bcdef \\
\hline TEX-262 & $3,00 \mathrm{f}$ & $3,00 \mathrm{~g}$ \\
\hline TEX-263 & $2,00 \mathrm{cde}$ & $2,00 \mathrm{bcdef}$ \\
\hline TEX-264 & $2,00 \mathrm{cde}$ & $2,00 \mathrm{bcdef}$ \\
\hline TEX-265 & $2,00 \mathrm{cde}$ & $2,00 \mathrm{bcdef}$ \\
\hline TEX-266 & $2,25 \mathrm{def}$ & $2,25 \mathrm{cdefg}$ \\
\hline TEX-267 & 2,33def & 2,33defg \\
\hline TEX-268 & $2,25 \mathrm{def}$ & $2,25 \mathrm{cdefg}$ \\
\hline Bônus $\mathrm{F}_{1}$ & $4,40 \mathrm{~g}$ & $5,00 \mathrm{~h}$ \\
\hline Bravo $F_{1}$ & $4,40 \mathrm{~g}$ & $4,60 \mathrm{~h}$ \\
\hline Débora Max & $4,40 \mathrm{~g}$ & $4,80 \mathrm{~h}$ \\
\hline Pérola $\mathrm{F}_{1}$ & $4,40 \mathrm{~g}$ & $4,60 \mathrm{~h}$ \\
\hline TOM-691 & 1,75 bcde & $2,25 \mathrm{cdefg}$ \\
\hline TOM-692 & 2,00 cde & 2,00bcdef \\
\hline TOM-693 & 2,00cde & $2,00 \mathrm{bcdef}$ \\
\hline TOM-694 & $1,00 \mathrm{a}$ & $1,50 \mathrm{abc}$ \\
\hline TOM-695 & 1,60abcd & 1,60abcd \\
\hline TOM-696 & $1,20 \mathrm{ab}$ & $1,20 \mathrm{a}$ \\
\hline TOM-697 & $1,40 \mathrm{abc}$ & $1,60 \mathrm{abcd}$ \\
\hline TOM-698 & $1,20 \mathrm{ab}$ & $1,40 \mathrm{ab}$ \\
\hline TOM-699 & $1,40 a b c$ & 1,80abcd \\
\hline
\end{tabular}


se entre 0 e $-1(-0,47$ e $-0,63$, respectivamente), o que é evidência de dominância incompleta do alelo Ty-1 (Tabela 3), da mesma forma como verificado por Zamir et al. (1994). A dominância incompleta oferecida pelo $T y-1$ possibilita a obtenção de híbridos de tomateiro com diferentes graus de resistência a begomovírus. Entretanto, o desenvolvimento de híbridos homozigotos para o loco $T y$-1, com maiores níveis de resistência, enfrenta limitação em razão dos alelos $T y$ - 1 - que confere tolerância a begomovírus - e $M i$ - alelo que confere resistência ao nematóide-dasgalhas, Meloidogyne spp. - estarem ligados em fase de repulsão (Zamir et al., 1994; Pan et al., 2000), o que dificulta a obtenção de linhagens resistentes, simultaneamente, a begomovírus e nematóides, pelos métodos convencionais de melhoramento.

Os padrões de bandas do marcador SSR-47 apresentados pelos tratamentos foram comparados aos das testemunhas LA-3473 (Ty-1/Ty-1, homozigoto resistente), LA-3475 $\left(T y-1^{+} / T y 1^{+}\right.$, homozigoto suscetível) e TEX-143 (Ty-1+/Ty-1, heterozigoto), os quais apresentaram, respectivamente, uma banda superior (de $191 \mathrm{pb}$ ), uma banda inferior (de $180 \mathrm{pb})$ e as duas bandas, pelo fato de o marcador ser co-dominante (Figura 1). Todos os 24 híbridos experimentais foram caracterizados, por meio do marcador molecular SSR-47, como heterozigotos para o loco $T y$-1, pelo fato de terem apresentado duas bandas, correspondentes a fragmentos de DNA amplificados de 191 pb e 180 pb, respectivamente. Esses híbridos, portanto, são portadores do alelo $T y-1$ que confere

Tabela 3. Estimativas dos contrastes entre os genótipos homozigotos resistentes, heterozigotos e suscetíveis a begomovírus, e dos componentes aditivos e de dominância, para o loco $T y-1$, aos 46 e 60 dias após a enxertia ${ }^{(1)}$.

\begin{tabular}{lcc}
\hline Contrastes & \multicolumn{2}{c}{ Estimativas } \\
\cline { 2 - 3 } & 46 dias & 60 dias \\
\hline $\begin{array}{l}\text { Genótipos homozigotos suscetíveis } \mathrm{x} \\
\text { genótipos homozigotos resistentes }\end{array}$ & $2,8911^{* *}$ & $3,0444^{* *}$ \\
$\begin{array}{l}\text { Genótipos suscetíveis x genótipos } \\
\text { heterozigotos }\end{array}$ & $2,1222^{* *}$ & $2,4826^{* *}$ \\
$\begin{array}{l}\text { Genótipos heterozigotos x genótipos } \\
\text { resistentes }\end{array}$ & $0,7722^{* *}$ & $0,5618^{* *}$ \\
\hline A & $1,4472^{* *}$ & $1,5222^{* *}$ \\
D & $-0,6750^{* *}$ & $-0,9604^{* *}$ \\
D/A & $-0,4664$ & $-0,6309$ \\
\hline
\end{tabular}

${ }^{1)} \mathrm{A}$, efeito aditivo no loco $T y-1$; D, efeito de dominância no loco $T y-1$; $\mathrm{D} / \mathrm{A}$, grau de dominância estimado no loco $T y-1 .{ }^{* * \text { Significativo a } 1 \% \text { de }}$ probabilidade, pelo teste $t$. tolerância a distintas espécies de begomovírus. Os híbridos comerciais apresentaram padrão de bandas semelhantes ao da testemunha suscetível LA-3475 e são suscetíveis a begomovírus. As linhagens avançadas utilizadas como genitoras na obtenção dos híbridos experimentais apresentaram padrão de banda semelhante ao da testemunha resistente LA-3473 e são, portanto, resistentes a begomovírus e homozigotas para o loco $T y$-1. Os resultados das avaliações de tolerância e suscetibilidade dos genótipos, obtidos através do teste de enxertia, demonstram concordância com os resultados obtidos com o marcador molecular SSR-47, confirmando sua eficiência na seleção visando à resistência a begomovírus.

Os rendimentos médios por hectare dos híbridos experimentais oscilaram de 108,89 $\mathrm{Mg} \mathrm{ha}^{-1}$, para o híbrido TEX-246, a 54,22 $\mathrm{Mg} \mathrm{ha}^{-1}$ para TEX-267. Os híbridos experimentais TEX-246, TEX-261, TEX-253, TEX-256, TEX-254, TEX-263, TEX-257, TEX-255, TEX-262, TEX-265, TEX-252, TEX-258, TEX-268, TEX-260, TEX-247, TEX-248, TEX-251 e TEX-245 apresentaram valores satisfatórios de produção total semelhante aos das testemunhas comerciais (Tabela 4). Para produção precoce, os valores variaram de 19,67 $\mathrm{Mg} \mathrm{ha}^{-1}$, para o híbrido TEX-263, a 3,11 $\mathrm{Mg} \mathrm{ha}^{-1}$, para o híbrido comercial Bravo $\mathrm{F}_{1}$, que foi o mais tardio. Os híbridos TEX-263, TEX-256, TEX-264, Bônus $F_{1}$, TEX-257, TEX-255, Pérola $F_{1}$, TEX-254 e TEX-265 foram os mais precoces. Já os híbridos TEX-260, TEX-259, TEX-268, TEX-249, TEX-251, TEX-250 e TEX-267 foram os mais tardios, com o híbrido comercial Bravo $\mathrm{F}_{1}$.

Para massa média do fruto, o híbrido comercial Bravo $F_{1}$ foi o que apresentou maior valor $(156,85 \mathrm{~g})$,

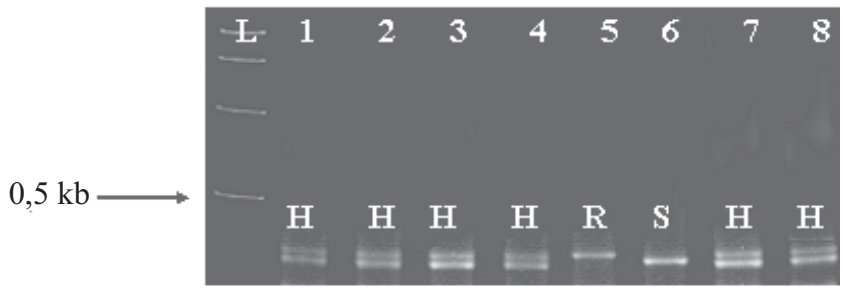

Figura 1. Padrão eletroforético de fragmentos de DNA amplificados para o marcador SSR-47, em genótipos de tomateiro. L, Ladder; 1, TEX-245; 2, TEX-249; 3, TEX-253; 4, TEX-143; 5, LA 3473; 6, LA 3475; 7, TEX-260; 8, TEX-265. H, heterozigoto; S, homozigoto suscetível; $\mathrm{R}$, homozigoto resistente. 
Tabela 4. Valores médios da produção total, produção precoce, massa média de fruto, firmeza inicial e meia-vida da firmeza de híbridos de tomateiro(1).

\begin{tabular}{|c|c|c|c|c|c|}
\hline Tratamentos & $\begin{array}{l}\text { Produção total } \\
\left(\mathrm{Mg} \mathrm{ha}^{-1}\right)\end{array}$ & $\begin{array}{c}\text { Produção precoce } \\
\left(\mathrm{Mg} \mathrm{ha}^{-1}\right)\end{array}$ & $\begin{array}{l}\text { Massa média do } \\
\text { fruto }\left(\mathrm{g} \text { fruto }{ }^{-1}\right)\end{array}$ & $\begin{array}{l}\text { Firmeza inicial } \\
\left(10^{4} \mathrm{~N} \mathrm{~m}^{-2}\right)\end{array}$ & $\begin{array}{l}\text { Meia-vida da } \\
\text { firmeza (dias) }\end{array}$ \\
\hline TEX-245 & $68,56 b c$ & 11,22 abcdef & $129,17 \mathrm{abcd}$ & $5,53 a$ & $23,23 a$ \\
\hline TEX-246 & $108,89 a$ & 13,83 abcdef & $148,63 \mathrm{ab}$ & $5,69 \mathrm{a}$ & $32,51 \mathrm{a}$ \\
\hline TEX-247 & $73,06 \mathrm{abc}$ & $12,05 \mathrm{abcdef}$ & $135,77 \mathrm{abcd}$ & $4,91 \mathrm{a}$ & $33,08 \mathrm{a}$ \\
\hline TEX-248 & $72,11 \mathrm{abc}$ & $12,22 \mathrm{abcdef}$ & $131,90 \mathrm{abcd}$ & $5,40 \mathrm{a}$ & $28,28 \mathrm{a}$ \\
\hline TEX-249 & $66,30 \mathrm{bc}$ & $6,84 \mathrm{def}$ & $133,44 \mathrm{abcd}$ & $5,76 a$ & $33,59 \mathrm{a}$ \\
\hline TEX-250 & $54,96 \mathrm{c}$ & $6,25 \mathrm{def}$ & $122,66 \mathrm{bcd}$ & $6,03 \mathrm{a}$ & $24,24 \mathrm{a}$ \\
\hline TEX-251 & $70,33 \mathrm{abc}$ & 6,44 def & $140,64 \mathrm{abc}$ & $6,42 \mathrm{a}$ & $23,48 \mathrm{a}$ \\
\hline TEX-252 & $74,63 \mathrm{abc}$ & $11,72 \mathrm{abcdef}$ & $147,36 a b c$ & $5,50 \mathrm{a}$ & $28,19 \mathrm{a}$ \\
\hline TEX-253 & $87,00 \mathrm{abc}$ & $10,50 \mathrm{abcdef}$ & $150,74 a b$ & $5,39 \mathrm{a}$ & $32,09 \mathrm{a}$ \\
\hline TEX-254 & $80,05 \mathrm{abc}$ & 14,36 abcde & $136,49 \mathrm{abcd}$ & $5,21 \mathrm{a}$ & $28,51 \mathrm{a}$ \\
\hline TEX-255 & $76,00 \mathrm{abc}$ & 14,66 abcde & $133,44 \mathrm{abcd}$ & $5,43 \mathrm{a}$ & $27,61 \mathrm{a}$ \\
\hline TEX-256 & $85,50 \mathrm{abc}$ & $19,00 \mathrm{ab}$ & $140,40 \mathrm{abc}$ & $5,49 \mathrm{a}$ & $28,88 \mathrm{a}$ \\
\hline TEX-257 & $76,17 \mathrm{abc}$ & $16,89 \mathrm{abcd}$ & $123,58 \mathrm{~cd}$ & $5,50 \mathrm{a}$ & $28,26 a$ \\
\hline TEX-258 & $73,91 \mathrm{abc}$ & $11,88 \mathrm{abcdef}$ & $130,60 \mathrm{abcd}$ & $5,37 \mathrm{a}$ & $24,49 \mathrm{a}$ \\
\hline TEX-259 & $66,39 b c$ & $7,72 \mathrm{cdef}$ & $131,37 \mathrm{abcd}$ & $5,41 \mathrm{a}$ & $25,73 a$ \\
\hline TEX-260 & $73,83 \mathrm{abc}$ & $8,61 \mathrm{bcdef}$ & $133,95 \mathrm{abcd}$ & $5,51 \mathrm{a}$ & $25,05 \mathrm{a}$ \\
\hline TEX-261 & $91,44 \mathrm{abc}$ & $12,95 \mathrm{abcdef}$ & $147,23 \mathrm{abc}$ & $5,64 \mathrm{a}$ & $25,88 \mathrm{a}$ \\
\hline TEX-262 & $75,83 \mathrm{abc}$ & $12,72 \mathrm{abcdef}$ & $141,88 \mathrm{abc}$ & $5,28 \mathrm{a}$ & $29,69 \mathrm{a}$ \\
\hline TEX-263 & $78,66 \mathrm{abc}$ & $19,67 \mathrm{a}$ & $124,36 \mathrm{~d}$ & $5,47 \mathrm{a}$ & $25,67 \mathrm{a}$ \\
\hline TEX-264 & $60,63 \mathrm{c}$ & $18,30 \mathrm{abc}$ & $106,01 \mathrm{bcd}$ & $5,90 \mathrm{a}$ & $24,04 \mathrm{a}$ \\
\hline TEX-265 & $75,56 a b c$ & 14,33abcde & $127,62 \mathrm{abcd}$ & $5,47 \mathrm{a}$ & $27,96 a$ \\
\hline TEX-266 & $66,50 \mathrm{bc}$ & $10,78 \mathrm{abcdef}$ & $126,29 \mathrm{abcd}$ & $5,71 \mathrm{a}$ & $27,46 a$ \\
\hline TEX-267 & $54,22 \mathrm{c}$ & $5,55 \mathrm{ef}$ & $117,68 \mathrm{bcd}$ & $5,81 \mathrm{a}$ & $30,41 \mathrm{a}$ \\
\hline TEX-268 & $73,83 \mathrm{abc}$ & $7,50 \mathrm{cdef}$ & $144,35 \mathrm{abc}$ & $5,96 \mathrm{a}$ & $26,31 \mathrm{a}$ \\
\hline Bônus $\mathrm{F}_{1}$ & $87,57 \mathrm{abc}$ & $17,23 \mathrm{abcd}$ & $142,48 \mathrm{abc}$ & $5,00 \mathrm{a}$ & $36,75 a$ \\
\hline Bravo $\mathrm{F}_{1}$ & $100,75 \mathrm{ab}$ & $3,11 \mathrm{f}$ & $156,85 \mathrm{a}$ & $5,59 \mathrm{a}$ & $23,03 a$ \\
\hline Débora Max & $92,39 \mathrm{abc}$ & $12,50 \mathrm{abcdef}$ & $145,24 \mathrm{abc}$ & $5,52 \mathrm{a}$ & $22,96 a$ \\
\hline Pérola $F_{1}$ & $90,78 \mathrm{abc}$ & $14,61 \mathrm{abcde}$ & $150,76 \mathrm{ab}$ & $5,17 \mathrm{a}$ & $29,59 \mathrm{a}$ \\
\hline CV (\%) & 15,77 & 28,91 & 7,06 & 7,88 & 20,23 \\
\hline
\end{tabular}

e não diferiu estatisticamente dos demais híbridos comerciais nem dos híbridos experimentais TEX-253, TEX-246, TEX-252, TEX-261, TEX-268, TEX-262, TEX-251 e TEX-256.

Foi possível verificar que, tanto os híbridos experimentais quanto os híbridos comerciais, exibiram valores de firmeza inicial dos frutos semelhantes, sem diferenças significativas entre eles.

\section{Conclusões}

1. Os híbridos experimentais TEX-245, TEX-246, TEX-247, TEX-248, TEX-249, TEX-250, TEX-251, TEX-252, TEX-253, TEX-254, TEX-255, TEX-256, TEX-257, TEX-258, TEX-259, TEX-260, TEX-261, TEX-262, TEX-263, TEX-264, TEX-265, TEX-266, TEX-267 e TEX-268 e as linhagens avançadas TOM-691, TOM-692, TOM-693, TOM-694, TOM-695, TOM-696, TOM-697, TOM-698 e TOM-699 apresentam resistência parcial a begomovírus.
2. O alelo $T y$-1 apresenta dominância incompleta para o caráter resistência a begomovírus.

3. Os híbridos experimentais TEX-246, TEX-261, TEX-253, TEX-256, TEX-262, TEX-252, TEX-251 e TEX-268 são bastante competitivos, quando comparados aos padrões comerciais.

4. Os resultados das avaliações de resistência a begomovírus, obtidos por meio do teste de enxertia, apresentam perfeita concordância com os resultados obtidos com o marcador molecular SSR-47, o que confirma a utilidade desse marcador para caracterização de genótipos de tomateiro quanto à presença do alelo $T y-1$ de resistência a begomovírus.

\section{Agradecimentos}

À Coordenação de Aperfeiçoamento de Pessoal de Nível Superior e à Fundação de Amparo à Pesquisa do Estado de Minas Gerais, pelo apoio financeiro; ao Conselho Nacional de Desenvolvimento Científico e Tecnológico, 
pela concessão de bolsa; à Universidade Federal de Lavras e à empresa HortiAgro Sementes Ltda., pela disponibilização de espaço e funcionários para realização dos experimentos.

\section{Referências}

BOITEUX,L.S.;OLIVEIRA,V.R.;SILVA, C.H.;MAKISHIMA,N.; INOUE-NAGATA, A.K.; FONSECA, M.E.N.; GIORDANO, L.B. Reaction of tomato hybrids carrying the $T y-1$ locus to Brazilian bipartite Begomovirus species. Horticultura Brasileira, Brasília, v.25, p.20-23, 2007.

CÁ, J.A. Obtenção de híbridos de tomate tipo longa vida com maior intensidade de coloração. 2005. 77p. Dissertação (Mestrado) - Universidade Federal de Lavras, Lavras.

CALBO, A.G.; CALBO, M.E. Medição e importância do potencial de parede. Revista Brasileira de Fisiologia Vegetal, v.1, p.41-45, 1989.

CALBO, A.G.; NERY, A.A. Medida de firmeza em hortaliças pela técnica de aplanação. Horticultura Brasileira, v.13, p.14-18, 1995.

FARIA, J.C.; BEZERRA, I.C.; ZERBINI, F.M.; RIBEIRO, S.G.; LIMA, M.F. Situação atual das geminiviroses no Brasil. Fitopatologia Brasileira, v.25, p.125-137, 2000.

FARIA, M.V.; MALUF, W.R.; RESENDE, J.T.V. de; ANDRADE-JÚNIOR, V.C.; NASCIMENTO, I.R. do; BENITES, F.R.G.; MENEZES, C.B. de; AZEVEDO, S.M. Mutantes rin, nor ${ }^{\mathrm{A}}$, $o g c$ e $h p$ em diferentes backgrounds genotípicos de tomateiro. Pesquisa Agropecuária Brasileira, v. 41, p.793-800, 2006.

FERREIRA, M.E.; GRATTAPAGLIA, D. Introdução ao uso de marcadores moleculares em análises genéticas. 3.ed. Brasília: Embrapa-Cenargen, 1998. 220p.

FRARY, A.; XU, Y.; LIU, J.; MITCHELL, S.; TEDESCHI, E.; TANKSLEY, S. Development of a set of PCR-based anchor markers encompassing the tomato genome and evaluation of their usefulness for genetics and breeding experiments. Theoretical and Applied Genetics, v.111, p.291-312, 2005.

LAPIDOT, M.; FRIEDMAN, M.; LACHMAN, O.; YEHEZKEL, A.; NAHON, S.; COHEN, S.; PILOWSKY, M. Comparison of resistance level to tomato yellow leaf curl virus among commercial cultivars and breeding lines. Plant Disease, v.81, p.1425-1428, 1997.
LOURENÇÃO, A.L.; MELO, A.M.T.; SIQUEIRA, W.J.; COLARICCIO, A.; MELO, P.C.T. Avaliação da resistência de acessos de tomateiro a tospovírus e a geminivírus. Horticultura Brasileira, Brasília, v.22, p.193-196, 2004.

MATOS, E.S.; SIQUEIRA, W.J.; LOURENÇÃO, A.L.; MELO, A.M.T.; SAWAZAKI, H.E.; SOUZA-DIAS, J.A.C.; COLARICCIO, A. Resistência de genótipos de tomateiro a um isolado de geminivírus do cinturão verde de Campinas, São Paulo. Fitopatologia Brasileira, v.28, p.159-165, 2003.

MORIONES, E.; NAVAS CASTILLO, J. Tomato yellow leaf curl virus, an emerging virus complex causing epidemics worldwide. Virus Research, v.71, p.123-134, 2000.

PAN, Q.; LIU, Y.S.; BUDAI-HADRIAN, O.; SELA M.; CARMEL-GOREN, L.; ZAMIR, D.; FLUHR, R. Comparative genetics of nucleotide binding site-leucine rich repeat resistance gene homologues in the genomes of two dicotyledons: tomato and arabidopsis. Genetics, v.155, p.309-322, 2000.

RIBEIRO, S.G.; AMBROZEVÍCIUS, L.P.; ÁVILA, A.C.; BEZERRA, I.C.; CALEGARIO, R.F.; FERNANDES, J.J.; LIMA, M.F.; MELLO, R.N.; ROCHA, H.; ZERBINI, F.M. Distribution and genetic diversity of tomato-infecting begomoviruses in Brazil. Archives of Virology, v.148, p.281-295, 2003.

SANTANA, F.M.; RIBEIRO, S.G.; MOITA, A.W.; MOREIRA JUNIOR, D.J.; GIORDANO, L.B. Sources of resistance in Lycopersicon spp. to a bipartite whitefly-transmitted geminivirus from Brazil. Euphytica, v.122, p.45-51, 2001.

SOL GENOMICS NETWORK. Markers for tomato chromosomes. Disponível em: <http://www.sgn.cornell.edu/>. Acesso em: 5 maio 2008.

ZAMIR, D.; EKSTEIN-MICHELSON, I.; ZAKAY, Y.; NAVOT, N.; ZEIDAN, M.; SARFATTI, M.; ESHED, Y.; HAREL, E.; PLEBAN, T.; VAN-OSS, H.; KEDAR, N.; RABINOWITCH, H.D.; CZOSNEK, H. Mapping and introgression of tomato yellow leaf curl virus tolerance gene, $T y-1$. Theoretical and Applied Genetics, v.88, p.141-146, 1994.

ZHOU,Y.C.; NOUSSOUROU, M.; KON, T.; ROJAS, M.R.; JIANG, H.; CHEN, L.F.; GAMBY, K.; FOSTER, R.; GILBERTSON, R.L. Evidence of local evolution of tomato-infecting begomovirus species in West Africa: characterization of tomato leaf curl Mali virus and tomato yellow leaf crumple virus from Mali. Archives of Virology, v.153, p.693-703, 2008.

Recebido em 21 de agosto de 2008 e aprovado em 13 de novembro de 2008 